\title{
Anti-biofim and Antibacterial Effect of Essential Oils and Their Major Compounds
}

\author{
Alessandra Farias Millezi 1, Roberta Hilsdorf Piccoli ${ }^{2 *}$, \\ José Maria Oliveira ${ }^{3}$, Maria Olivia Pereira ${ }^{3}$ \\ ${ }^{1}$ Federal Catarinense Institute of Education Science and \\ Technology, Campus Concordia, Concórdia, Brasil \\ ${ }^{2}$ Federal University of Lavras - Department of Food Science, Lavras, Brazil \\ ${ }^{3}$ IBB-Institute for Biotechnology and Bioengineering, Centre of Biological \\ Engineering, Universidade do Minho, 4710-057 Braga, Portugal
}

Received 28 August 2014; accepted in revised form 30 November 2014

\begin{abstract}
Essential oils are plant secondary metabolites commonly used in traditional medicine to treat infectious diseases. Along with their compounds, oils can contribute to development of new antimicrobial/antibiofilm products. Our study evaluated antibacterial activity of essential oils and their major compounds on Escherichia coli and Staphylococcus aureus planktonic cells and anti-biofilm activity. The effect of essential oils and their major compounds on biofilm and planktonic cells was assessed by quantifying the number of viable cells $(\mathrm{CFU})$. Biomass quantification (absorbance $=\mathrm{OD}_{570 \mathrm{~nm}}$ ) was also performed to evaluate anti-biofilm activity. Planktonic cells were more susceptible to the action of agents. Escherichia coli was reduced by $100 \%$ with cinnamon and palmarosa oil. The treatment showed an interesting anti-biofilm activity, whereas green tea essential oil and its major compound, terpinen-4-ol, yielded less effective results. Reduction of viable cells in biofilm biomass was significant. Although our research is one of the first experiments in anti-biofilm activity of essential oils and their compounds against Escherichia coli and Staphylococcus aureus, pharmacological data confirm that the materials used in the trial do not pose health risk. Thus, essential oils and their compounds can be safely used in research to identify new antibacterial and anti-biofilm products against pathogenic bacteria.
\end{abstract}

Key words: Natural antimicrobial, bacterial biofilms, pathogen bacteria.

\section{Introduction}

Biofilms comprise highly structured matrix-enclosed communities ${ }^{4}$ and represents a mode of growth that allows bacteria to both survive in hostile environments and colonize new niches through dispersal mechanisms ${ }^{15.22 .31}$. Furthermore, biofilm bacteria show coordinated behavior by building complex three-dimensional structures and functionally heterogeneous bacterial communities ${ }^{15,37}$. Biofilm cells express genes in patterns ${ }^{34}$ differently from their planktonic counterparts. Direct observation shows that biofilms are ubiquitous in both natural and pathogenic ecosystems ${ }^{3,5}$; however, planktonic cultures in the systems should be studied as well. One of the advantages of planktonic cells forming biofilms on the surface is protection against action of antibiotics and antimicrobial agents ${ }^{10,14,23}$. Over the last two decades several publications have considered the genus Staphylococcus cap-able of forming biofilm bacteria, causing infections defined as "chronic infections associated with biopolymers" ${ }^{12}$. After biomaterial implantation, such staphylococcal infections may occur early or late ${ }^{19}$. Due to its ability

*Corresponding author (Roberta Hilsdorf Piccoli)

E-mail: < rhpiccoli@ufla.br>

(C) 2016, Har Krishan Bhalla \& Sons 
to adhere to inert surfaces, S. aureus has become the major agent of hospital-acquired infections associated with biopolymers worldwide ${ }^{17,19}$.

Escherichia coli can behave as intestinal commensal, diarrheagenic and extra intestinal pathogenic agent. It is responsible for most community and hospital-acquired Gram-negative bacterial infections. E.coli is found in the gut flora, also colonizing the genital mucosa. Thus, bacteria may enter the urinary system and adhere to mucosal surfaces and implant devices ${ }^{9}$. Adherence and formation of biofilms cause infections that contribute to significant morbidity rate, although they may be short term cases ${ }^{9}$.

Thus, alternative strategies or effective agents to act against biofilm-producing micro-organisms are of great interest. Natural drugs could be an interesting approach to limit emergence and spread of such organisms, which are currently difficult to fight. Recently, there has been considerable interest in the study of plant materials as sources of new compounds ${ }^{18,33}$ for processing therapeutic agents. One approach could be the use of essential oils, which have been found to be potential and safe antibacterial agents ${ }^{29}$. The functional use of natural essential oils as antibacterial agents has been increasing in medicine and dentistry. Mouthwashes containing essential oils can kill oral microorganisms by inhibiting their enzyme activity and breaking down their cell walls ${ }^{32}$. Essential oils also inhibit coaggregation between early and late colonizers, e.g. Gram-negative anaerobic periodontopatho-gens ${ }^{32}$. In addition, essential oils inhibit formation of bacterial biofilms on surfaces such as polystyrene ${ }^{13}$.

In our study, three essential oils were selected based on their use as antimicrobial agents in Brazilian traditional medicine. We also used their respective major compounds to test and compare effects on planktonic bacteria and biofilms. Thus, our study evaluated anti-biofilm and antibacterial activity of essential oils and their major compounds in planktonic cells of E.coli and S.aureus.

\section{Materials and methods \\ Essential oils and major compounds}

Essential oils of Cinnamomum zeylanicum (cinnamon); Cymbopogon martini (palmarosa) and Melaleuca alternifolia (green tea) extracted from plant leaves by hydro-distillation were purchased from Ferquima Indústria e Comércio Ltda. (Vargem Grande, São Paulo, Brazil). According to the company, the major compound of cinnamon is eugenol (86\%); geraniol $(86 \%)$ in palmorosa oil; and terpine-4-ol (48 \%) in green tea oil. The isolated major compounds were purchased from Sigma Aldrich.

\section{Microorganism and inoculum standardization}

We used Escherichia coli ATCC 25922 and Staphylococcus aureus ATCC 24922. Standardization of number of cells was determined by calibration curve. Cultures were grown on Trypticase Soy Agar (TSA, Merck, Portugal) added to Petri dishes and incubated at $37^{\circ} \mathrm{C}$ for 24 hours. Some colonies formed on TSA surface were removed and transferred to Erlenmeyer flasks containing $50 \mathrm{ml}$ of Trypticase Soy Broth (TSB, Merck, Portugal), which were incubated at $37^{\circ} \mathrm{C}$ until reaching the number of cells necessary for the experiment, approximately $10^{8} \mathrm{CFU} / \mathrm{ml}$.

\section{Effect of essential oils on growth of plank- tonic cells}

The solution was formed in accordance with the model proposed by Oliveira et al. ${ }^{30}$ with some modification, as ethanol was replaced by dimethyl sulfoxide (DMSO). We used concentrations 0.48 , 0.96 and $1.92 \%$ of essential oils, while concentration of major compounds corresponded to oil concentration. The solution contained DMSO, $0.85 \%$ saline water, $0.5 \%$ Tween 80 , and TSB. Aliquots of $100 \mu 1$ were dispensed into 96-well micro-plates (Orange Scientific, Braine-1'Alleud, Belgium) with $100 \mu 1 \mathrm{TSB}$ containing $10^{8} \mathrm{CFU} /$ $\mathrm{ml}$. Wells containing only TSB served as control. The plates were incubated in aerobic conditions for $24 \mathrm{~h}$ at $37^{\circ} \mathrm{C}$ in orbital shaker at $120 \mathrm{rpm}$. After incubation, planktonic cells were collected for quantification of viable cells $(\mathrm{CFU} / \mathrm{mL})$.

\section{Effect of essential oils and compounds on bac- terial biofilms}

Biofilms were developed on 96-well microtiter plates (Orange Scientific, Braine-1'Alleud, Belgium) in solutions containing essential oils and their major compounds. Bacterial cell suspensions (100 $\mu \mathrm{l}$ of $1 \times 10^{8}$ cells $/ \mathrm{ml}$ in TSB), essential oils and 
compounds $(100 \mu \mathrm{l}$ of the concentrations previously described) were pipetted into each well and incubated for $24 \mathrm{~h}$ at $37^{\circ} \mathrm{C}$ in orbital shaker at 120 rpm.

\section{Quantification of cultivable cells}

Planktonic cells were quantified by plating on TSA medium. To quantify biofilm cells, the wells were washed in sterile water to remove planktonic bacteria. Viable biofilm cells were removed by sonication and serially diluted. Samples were then plated on TSA medium, and plates were incubated at $37^{\circ} \mathrm{C}$ in aerobic incubator for $18 \mathrm{~h}$ prior to enumeration. The number of cultivable bacterial cells was determined and expressed as Log $\mathrm{CFU} / \mathrm{mL}$ (planktonic) and Log CFU/ $\mathrm{cm}^{2}$ (sessile). Assays were performed on three separate occasions.

\section{Biomass quantification by Crystal Violet staining}

Biomasses of single and mixed biofilms were quantified by adapting the crystal violet $(\mathrm{CV})$ staining method by Stepanovic' et al. ${ }^{36}$. For fixing, we added $200 \mu 1$ of $99 \%$ methanol (Vaz Pereira, Portugal) to each well containing adhered cells or biofilms treated with essential oils, as previously described. After 15 minutes the methanol was removed, and the plates were allowed to dry at room temperature. Then we added $200 \mu 1$ of crystal violet stain (CV; $1 \% \mathrm{v} / \mathrm{v})$ (Merck, Portugal) to all wells. After 5 minutes, CV excess was removed and plates were gently washed in water. Finally, $230 \mu \mathrm{l}$ of acetic acid (33\% v/v) (Pronalab, Portugal) were added to the wells to dissolve $\mathrm{CV}$ stain, and the absorbance was measured at 570 nm. All assays were performed in triplicate on three separate occasions.

\section{Statistical analysis}

Data were analyzed with GraphPad Prism ${ }^{\circledR}$. One-way ANOVA tests were performed and $\mathrm{p}<0.01$ was considered significant.

\section{Results}

Antimicrobial activity against planktonic cells

Essential oils and their major compounds showed significant antimicrobial potential $(\mathrm{P}<0.05)$ against planktonic bacteria of $E$. coli and $S$. aureus
(Fig. 1). Escherichia coli was more susceptible to the action of cinnamon and palmarosa oils at concentration $0.96 \%$, with $100 \%$ reduction of cell growth. The lowest concentrations were also considered effective, as reductions were greater than $5 \log$ CFU. Eugenol and geraniol reduced more than $90 \%$ planktonic cells of E. coli (Fig. 1). Essential oil of green tea was the least effective, as it reduced only 1.95 and $2.03 \log$ CFU at concentrations $0.12 \%$ and $0.48 \%$ respectively. However, reduction was over $5 \log$ CFU at concentration $0.96 \%$ (Fig. 1) while its major compound, geraniol, reduced more than $7 \log \mathrm{CFU}$ for both (Fig. 1).

Reduction of planktonic cells of $S$. aureus was also significant $(p<0.05)$ (Fig. 1 and 2). Viable cells in biofilms were more resistant to essential oil action than planktonic bacteria (Fig. 2). Green tea essential oil showed low anti-biofilm potential while its major compound tepinene-4-ol had no significant anti-biofilm activity against $E$. coli $(\mathrm{P}>0.05)$. The maximum reduction against $E$. coli was 1.66 $\log$ CFU at concentration $0.96 \%$. Palmarosa oil had the greatest anti-biofilm potential at concentration $0.96 \%$, reducing $3.04 \log$ CFU. However, as well as geraniol, anti-biofilm potential was less than $50 \%$ at lower concentrations. Cinnamon essential oil was the most effective against viable biofilm cells of $E$. coli, with all concentrations showing reduction over $3 \log$ CFU. At concentration $0.96 \%$, reduction was over $75 \%$. Eugenol, however, did not show the same efficiency, decreasing only $1.88 \log$ CFU (Fig. 3).

The action of green tea, palmarosa and cinnamon essential oils was significant $(\mathrm{P}<0.05)$ in biomass reduction of $E$. coli biofilm (Fig. 3). The major compounds were also effective (Fig. 3). Formation of $E$. coli biomass was inhibited by more than $93 \%$ in treatments with oils and their major compounds.

Reductions of viable biofilm cells of $S$. aureus were lower than in E. coli. At concentration $0.96 \%$ green tea essential oil showed significant decrease ( $\mathrm{P}<0.05)$ (Fig. 3), although only reaching $1.76 \log$ CFU. Terpinen-4-ol was not effective to prevent formation of S. aureus biomass $(\mathrm{P}$ $>0.05$ ). Palmarosa essential oil was significantly effective at concentrations $0.48 \%$ and $0.96 \%$, reducing 3.12 and $4.17 \log$ CFU respectively, while 

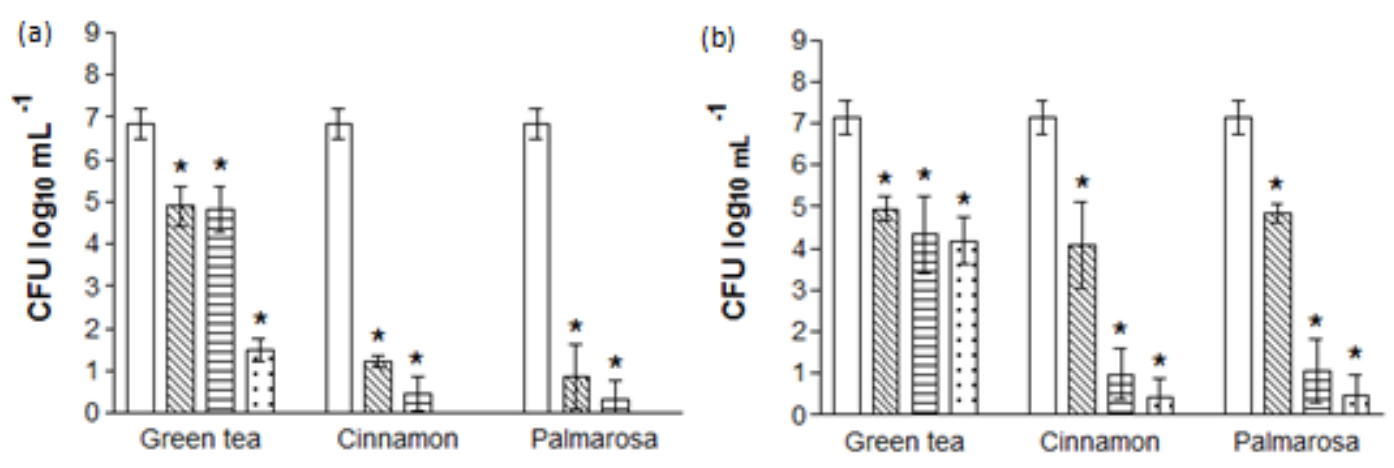

$\square 0,0 \lll 0,12 \% \rightleftarrows 0,48 \% \varpi 0,96 \%$
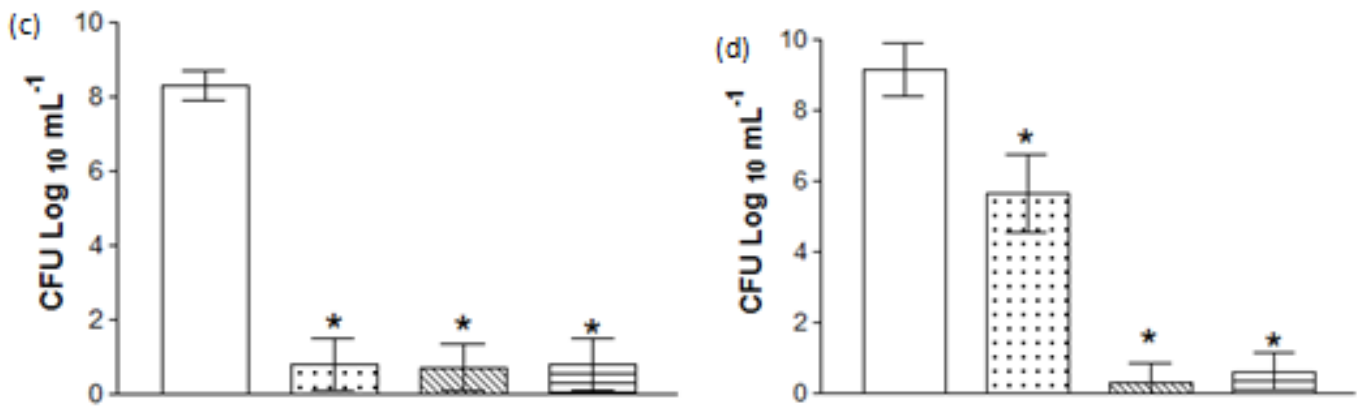

$\square$ Control $\square$ Terpine-4-ol $\amalg$ Geraniol $\rightleftarrows$ Eugenol

Figure 1. Inhibition E. coli (a) and S. aureus (b) viable plankctonic cells for different concentrations of essential oil and E. coli (c) and S. aureus (d) for compounds majority of essential oils
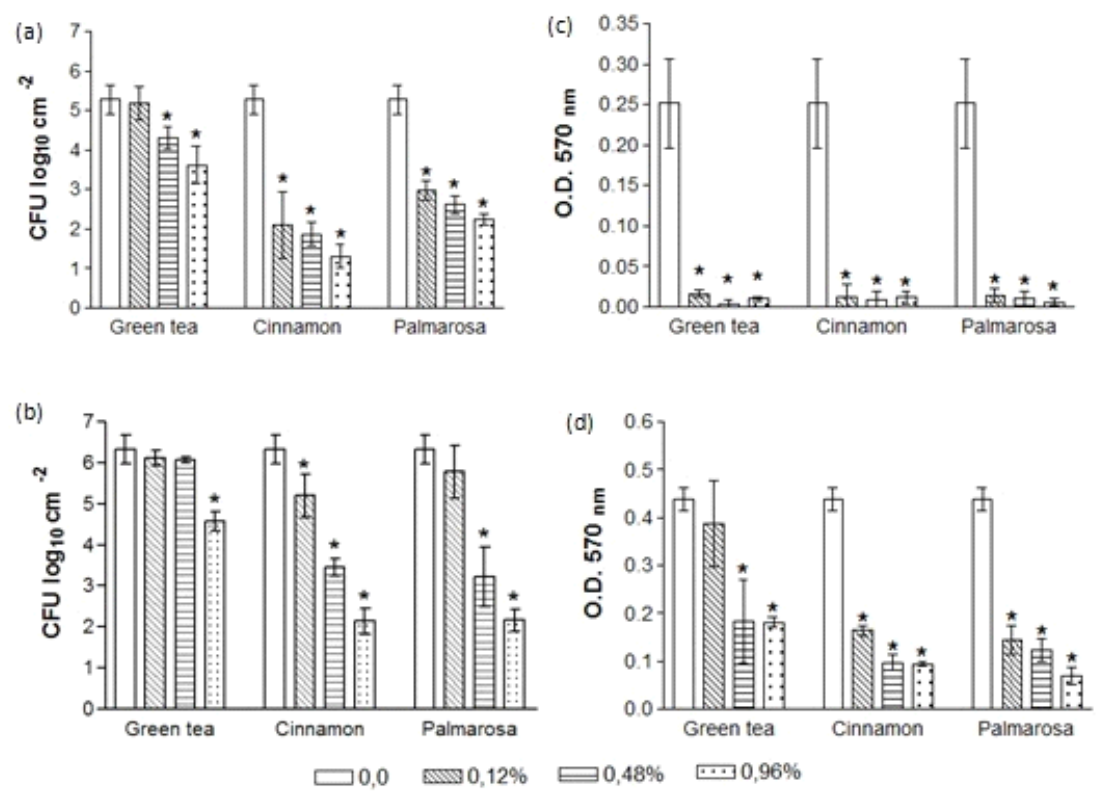

Figure 2. Activity antibiofilm of essential oils on E. coli (a) and S. aureus (b) cells cultivated in biofilms and E. coli (c) and S. aureus (d) biomass 

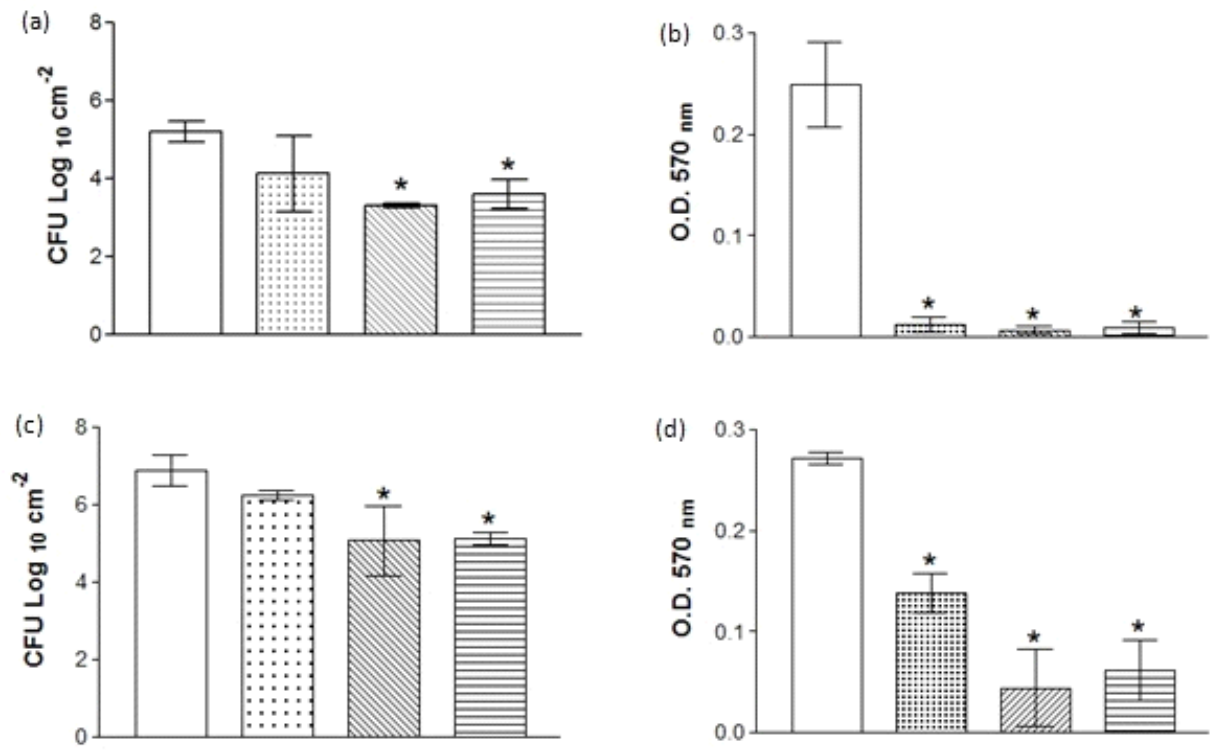

$\square$ Control $\rightleftharpoons$ Terpine-4-ol

आmE Eugenol 戸Geraniol

Figure 3. Activity antibiofilm diferente major compounds of essential oil of E. coli (a) and S. aureus (c) cells cultivated in simple biofilm and E. coli (b) and S. aureus (d) biomass

geraniol reduced only $25 \%$. As observed in $E$. coli, cinnamon essential oil also showed greater anti-biofilm capacity against $S$. aureus. Cinnamon essential oil at concentration $0.96 \%$ reduced $66 \%$ viable biofilm cells of $S$. aureus, equivalent to $4.19 \log \mathrm{CFU}$; however, the same efficiency was not observed for eugenol, which decreased $29.22 \%$ cells, equivalent to $2 \log$ CFU.

The effect of essential oils and compounds in $S$. aureus biomass was good except for green tea oil at concentration $0.12 \%$, which did not prevent biomass formation $(\mathrm{P}>0.05)$. Palmarosa and cinnamon essential oils as well as their major compounds showed greater ability to inhibit biomass formation over $62 \%$. Palmarosa oil at concentration $0.96 \%$ showed the greatest reduction (86.04 \%) (Fig.3).

\section{Discussion}

Essential oils and their compounds are known to be active against a wide variety of microorganisms, including Gram-positive and Gram-negative bacteria $7,8,13,16$ in both planktonic form ${ }^{24,26}$ and biofilm ${ }^{25,27,30}$. Bacteria in biofilm mode of growth have been much more resistant to antibiotics than their planktonic counterparts ${ }^{21,33}$. In our study, such phenomenon also occurred in the action of essential oils and their compounds. This result confirmed the greater resistance of viable bacterial cells in biofilm rather than in planktonic mode for both E. coli and S. aureus.

According to Stoodley et al., ${ }^{37}$, planktonic phenotype differs profoundly from biofilm phenotype, which involves the expression of a large number of genes that allow sessile bacteria to better resist to environmental stresses and adverse conditions, as well as to the presence of antibiotics and antimicrobial agents. In a recent study, mature biofilms of $P$. aeruginosa have shown a protein profile radically different from planktonic bacteria grown in chemostats ${ }^{34}$. As much as $50 \%$ of detectable proteome (over 800 proteins) have shown a six-fold or greater difference in expression. Of these proteins, more than 300 were detected in mature biofilm samples undetectable in planktonic bacteria. The identified proteins fall into five major classes: metabolism, phospholipids and LPS-biosynthesis, membrane transport and secretion, as well as adaptation and protective mechanisms ${ }^{34}$.

Several studies have addressed the use of natural compounds as antimicrobial agents 18,29,33,38. 
However, little has been reported on the effect of cinnamon, palmarosa and green tea essential oils and their respective major compounds eugenol, geraniol and terpinene-4-ol against pathogenic bacteria. According to our knowledge, this is the first study investigating anti-biofilm action of essential oils of cinnamon and palmarosa and their major compounds against $S$. aureus and E. coli.

Our study showed an interesting anti-biofilm action of essential oils and their major compounds against S. aureus and E. coli. Most treatments produced good action on viable biofilm cells and biomass. Essential oils had a better performance than their individual compounds. According to Sandasi et al. ${ }^{33}$, some compounds of essential oils ( $\alpha$-pinene, linalool, 1.8-cineole, geranyl acetate) were unable to inhibit biofilm growth in Listeria monocytogenes. The authors suggest that resistance to inhibition could be the fact that compounds used individually do not have the same activity as oils. Studies have shown that antimicrobial effect of essential oils is due to interaction between oils and their compounds instead of depending on individual components ${ }^{30}$. Thus, our results were better against $E$. coli than against $S$. aureus, corroborating the results of experiments carried out by Budzynski et al. ${ }^{2}$, in which Gramnegative bacteria were very susceptible to damage caused by essential oils of Melaleuca alternifolia, Lavandula angustifolia and Melissa officinalis and some of their major compounds ( $\alpha$-terpineol, terpinen-4-ol, linalool, linalyl acetate).

Strong and fast anti-biofilm activity of TTO was noticed against $E$. coli, which was eradicated within 1 hour exposure to concentration $0.78 \%{ }^{2}$. However, only planktonic cells were completely eradicated in our study. Differences in the reported data could be due to many factors including differences in the strains, concentration and chemical composition of essential oils, time of exposure to oils, growth stage of biofilm, and nature of surface to which organisms adhere ${ }^{1,11,20}$.

The findings of this study highlight the promising role of compounds derived from plant secondary metabolism, especially essential oils, as antibacterial and anti-biofilm agents. Literature data on the pharmacological compounds used in this experiment suggest they pose no risk to human or animal health ${ }^{6,35}$. Therefore, it may be worth further investigation.

\section{Acknowledgments}

The authors thank the Coordenação de Aperfeiçoamento de Pessoal de Nível Superior (CAPES) for the first author's scholarship, the Fundação de Amparo à Pesquisa do Estado de Minas Gerais (FAPEMIG) for the financial support, the Foundation for Science and Technology and European Community fund European Regional Development Fund (FEDER), in the ambit of the Project PTDC/SAUESA/ 6460912006/ FCOMP-01-0124-FEDER-007480.

\section{References}

1. Burt, S.A., Reinders, R.D. (2004). Antibacterial activity of selected plant essential oils against Escherichia coli O157:H7. Let. Appl. Microb. 36: 162-167.

2. Budzyñska, A., Wiêckowska-Szakiel, M., Kalemba, B.D. and Ró-Alska, B. (2011). Antibiofilm Activity of Selected Plant Essential Oils and their Major Components. Pol. J. Microb., 60: 35.41 .

3. Costerton, J.W., Geesey, G.G., Cheng, K.J. (1978). How bacteria stick. Sci. American. 238: 86-95.

4. Costerton, J.W., Stewart, P.S., Greenberg, E.P. (1999). Bacterial biofilms: a common cause of persistent infections. Sci. 284: 1318-22.

5. Costerton, J.W., Stewart, P.S. (2001). Battling biofilms. Sci. American. 285: 75-81.

6. Chami, N., Bennis, S., Chami, F., Aboussekhra, A., Remmal, A. (2005). Study of anticandidal activity of carvacrol and eugenol in vitro and in vivo. Oral Microb. Immun. 20: 106-111.

7. Deans, S.G., Ritchie, G. (1987). Antibacterial properties of plant essential oils. Int. J. Food Microb., 5: 165-180. 
8. Duarte, M.C.T., Leme, E.E., Delarmelina, C., Soares, A.A., Figueira, G.M. , A. (2007). Activity of essential oils from Brazilian medicinal plants on Escherichia coli. J. Ethn. 111: 197201.

9. Esmerino, L.A., Gonçalves, G.L., Schelesky, M.E. (2003). Perfil de sensibilidade antimicrobiana de cepas de Escherichica coli isoladas de infecções urinárias comunitárias. Ciên. Biol. Saúde, 9: 31-39.

10. Gilbert, P., Allison, D.G., McBain, A.J. (2002). Biofilms in vitro and in vivo: do singular mechanisms imply cross-resistance? J. Appl. Microb., 92: 98-110.

11. Gobbo-Neto, L., Lopes, N.P. (2007). Plantas medicinais: fatores de influência no conteúdo de metabolitos secundários. Quím. Nova, 30: 374-381.

12. Götz F. (2002). Staphylococcus and biofilms. Mol. Microb., 43: 1367-1378.

13. Gursoy, U.K.M., Gursoy, O.V., Gursoy, L., Cakmakci, E., Kononen, V.J. (2009). Antibiofilm properties of Satureja hortensis L. essential oil against periodontal pathogens. Anaerobe, 15: 164-167.

14. Hall-Stoodley, L., Stoodley, P. (2009). Evolving concepts in biofilm infections. Cell Microb., 11: 1034-1043.

15. Hall-Stoodley, L., Costerton, J.W., Stoodley, P. (2004). Bacterial biofilms: from the natural environment to infectious diseases. Nat. Rev., 2: 95-108.

16. Helander, I.M., Alakomi, H., Latva-Kala, K., Mattila-Sandholm, T., Pool, I., Smid, J., Gorris, L.G.M., Von Wright, A. (1998). Characterization of the action of selected essential oil components on Gram-negative bacteria. J. Agr. Food Chem., 46: 3590-3595.

17. Izano, E.A., Amarante, M.A., Kher, W.B., Jeffrey, B. (2008). Differential roles of poly-Nacetylglucosamine surface polysaccharide and extracellular DNA in Staphylococcus aureus and Staphylococcus epidermidis biofilms. Appl. Env. Microb., 74: 470-476.

18. Knowles, J.R.S., Roller, S., Murray, D.B., Naidu, A.S. (2005). Antimicrobial action of carvacrol at different stages of dual-species biofilm development by Staphylococcus aureus and Salmonella enterica serovar Typhimurium. Appl. Env. Microb. 71: 797-803.

19. James, N.R., Jayakrishnan, A. (2003). Surface thiocyanation of plasticized poly (vinyl chloride) and its effect on bacterial adhesion. Biomaterials, 24: 2205-2212.

20. Leonard, C.M., Virijevic, S., Regnier, T., Combrinck, S. (2010). Bioactivity of selected essential oils and some components on Listeria monocytogenes biofilms. S. Afr.. J. Bot., 76: 676-680.

21. Lewis, K. (2001). The riddle of biofilm resistance. Ant.Agents Chemoth., 45: 999-1007.

22. Mai-Prochnow, A., Lucas Elio, P., Egan, S., Thomas, T., Webb, S.J., Sanchez-Amat, A., Kjelleberg, S. (2008). Hydrogen peroxide linked to lysine oxidase activity facilitates biofilm differentiation and dispersal in several gram-negative bacteria. J. Bact..190: 5493-5501.

23. Mah, T.F., O'Toole, G.A. (2001). Mechanisms of biofilm resistance to antimicrobial agents. Trends Microb., 9: 34-39.

24. Millezi, F.M., Pereira, M.O., Batista, N.N., Camargos, N., Auad, I., Cardoso, M., Das, G., Piccoli, R.H. (2012a). Susceptibility of monospecies and dual-species biofilms of Staphylococcus aureus and Escherichia coli to essential oils. J. Food Saf., 32: 351-359.

25. Millezi, A.F., Caixeta, D.S., Rossoni, D.F., Cardoso, M.G., Piccoli, R.H. (2012b). In vitro antimicrobial properties of plant essential oils thymus vulgaris, cymbopogon citratus and laurus nobilis against five important foodborne pathogens. Ciênc. Tecnol. Ali. 32: 167-172.

26. Millezi, A.F., Baptista, N.N., Caixeta, D.S., Rossoni, D.F., Cardoso, M.G., Piccoli, R.H. (2014). Caracterização e atividade antibacteriana de óleos essenciais de plantas condimentares e medicinais contra Staphylococcus aureus e Escherichia coli. Rev. Bras. Plant. Med. 16(1): 18-24. 
27. Millezi, A.F., Cardoso, M., Das, G., Alves, E., Piccoli, R.H. (2013). Reduction of Aeromonas hidrophyla biofilm on stainless stell surface by essential oils. Braz. J. Microb., 44(1): 73-80.

28. Naves, P., Prado, G., Huelves, L., Gracia, M., Ruiz, V., Blanco, J., Dahbi, G., Blanco, M., Ponte, M.C., Soriano, F. (2008). Correlation between virulence factors and in vitro biofilm formation by Escherichia coli strains. Microb. Path. 45: 86-91.

29. Nostro, A., Roccaro, A.S., Bisignano, G., Marino Cannatelli, M.A., Pizzimenti Cioni, P., Procopio, F., Blanco, A.R. (2007). Effects of oregano, carvacrol and thymol on Staphylococcus aureus and Staphylococcus epidermidis biofilms. J. Med. Microb., 56: 519-523.

30. Oliveira, M.M.M., Brugnera, D.F., Alves, E., Piccoli, R.H. (2010). Disinfectant action of Cymbopogon sp. essential oils in different phases of biofilm formation by Listeria monocytogenes on stainless steel surface. Food Control. 21: 549-553.

31. Purevdorj Gage, B., Costerton, W.J., Stoodley, P. (2005). Phenotypic differentiation and seeding dispersal in non-mucoid and mucoid Pseudomonas aeruginosa biofilms, Microb., 145: 1569-1576.

32. Quhayoun, J.P. (2003). Penetrating the plaque biofilm: impact of essential oil, Mouthwash, 30: $10-12$.

33. Sandasi, M., Leonard, C.M., Viljoen, A.M. (2008). The effect of five common essential oil components on Listeria monocytogenes biofilms. Food Control, 19: 1070-1075.

34. Sauer, K., Camper, A., Ehrlich, D.G., Costerton, J.W., Davies, D.G. (2002). Pseudomonas aeruginosa displays multiple phenotypes during development as a biofilm. J. Bact.. 184: 11401154.

35. Stammati, A., Bonsi, P.F., Zucco, R., Moezelaar, H., Alakomi, L., Von, Wright, A. (1999). Toxicity of selected plant volatiles in microbial and mammalian short-term assays. Food Chem. Toxic. 37: 813-823.

36. Stepanovic, S., Vukovic, D., Dakic, I., Savic, B., Švabic-Vlahovic, M. (2000). A modified microtiter-plate test for quantification of staphylococcal biofilm formation. J. Microb. Meth. 40: 175-179.

37. Stoodley, P., Cargo, R., Rupp, C.J., Wilson, S., Klapper, I. (2002). Biofilm mechanics and shear-induced deformation and detachment. J. Ind. Microb. Biotech. 29: 361-368.

38. Trentin, D.D., Giordani, R.B., Zimmer, K.R., Silva, A.G.D., Silva, M.V.D., Santos Correia, M.T.D., Baumvold, I.J.R., Macedo, A.J. (2011). Potential of medicinal plants from the Brazilian semi-arid region (Caatinga) against Staphylococcus epidermidis planktonic and biofilm lifestyles. J. Ethnop. 137: 327- 335. 